\title{
Pilomatrical carcinoma - a case report and review of the literature
}

\section{Vladimír Bartoš ${ }^{1}$, Milada Kullová}

\author{
${ }^{1}$ Department of Pathology, Faculty Hospital in Žilina, Slovakia, ${ }^{2}$ Department of Dermatovenerology, Faculty Hospital in \\ Žilina, Slovakia
}

Corresponding author: Dr. Vladimír Bartoš, E-mail: vladim.bartos@gmail.com

\begin{abstract}
We report a case of an 85-year-old man, who presented with a polypoid skin tumor in the left lumbal region. Histology revealed a malignant tumor composed predominantly of pleomorphic basaloid cell population with a high mitotic and proliferative activity. This cellular component was admixed with aggregates of anuclear cells with eosinophilic cytoplasm reminiscent of "shadow” cells seen in pilomatrixoma, as well as with whorls of keratin material reminiscent of squamoid pearls. Immunohistochemically, the basaloid tumor part was positive for CD10, p120catenin and CD138 and very sporadically positive for cytokeratin 19 and BerEP4. Cytokeratin 20 was negative and epithelial membrane antigen labelled only eosinophilic squamoid structures. In some areas, numerous interspersed dentritic melanocytes strongly immunoreactive for S-100 protein were arranged singly and in larger expansile nests within basaloid tumor mass. Histopathology and immunoprofile of lesion favored a diagnosis of pilomatrical carcinoma with intratumorous melanocytic proliferation. To the best of our knowledge, only a few such cases have been described untill now.
\end{abstract}

Key words: Pilomatrical carcinoma; Pilomatrixoma; Adnexal tumors

\section{INTRODUCTION}

Pilomatrical carcinoma $(\mathrm{PC})$ is a very rare low-grade cutaneous malignancy with matrical differentiation, considered to be the malignant counterpart of pilomatrixoma. It was first described in 1980 by Lopansri and Mihm [1] and until now, about 140 cases have been published in the English literature [2]. Given the rarity of this neoplasm, there is impossible to estimate its incidence, and knowledge on etiology, pathogenesis and biological behaviour is only sparse. Here, we report an additional case of PC with uncommon histological feature and provide an up to date review of the literature.

\section{CASE PRESENTATION}

An 85-year-old man with a history of multiple cutaneous basal cell carcinomas presented with a polypoid skin tumor in the left lumbal region. He visited a dermatology outpatients department. On physical examination, the lesion was sharply demarcated, dark-brow in color and measured 12x8x6 mm. A presumptive clinical diagnosis of BCC was made. The patient was reffered to the hospital, when a total surgical excision of tumor had been performed.

\section{Histopathology and Immunohistochemistry}

Biopsy specimen was completely processed using standard hematoxylin and eosin stained paraffin sections along with a wide spectrum of immunohistochemical markers, summarized in Table 1. Histology revealed solid tumor formations, which were predominantly composed of pleomorphic basaloid cell population with frequent mitoses. This cellular component was admixed with multiple aggregates of anuclear cells with eosinophilic cytoplasm reminiscent of "shadow” cells seen in pilomatrixoma, as well as with whorls of pink keratin material reminiscent of squamoid pearls (Figs. 1 and 2). There was very high mitotic and proliferative activity. The

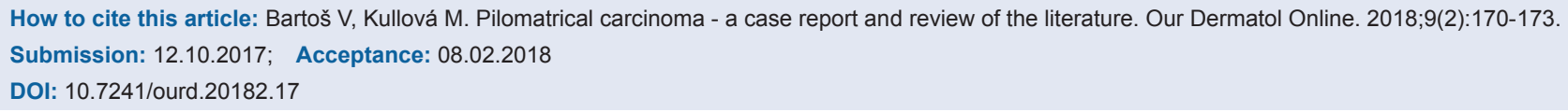




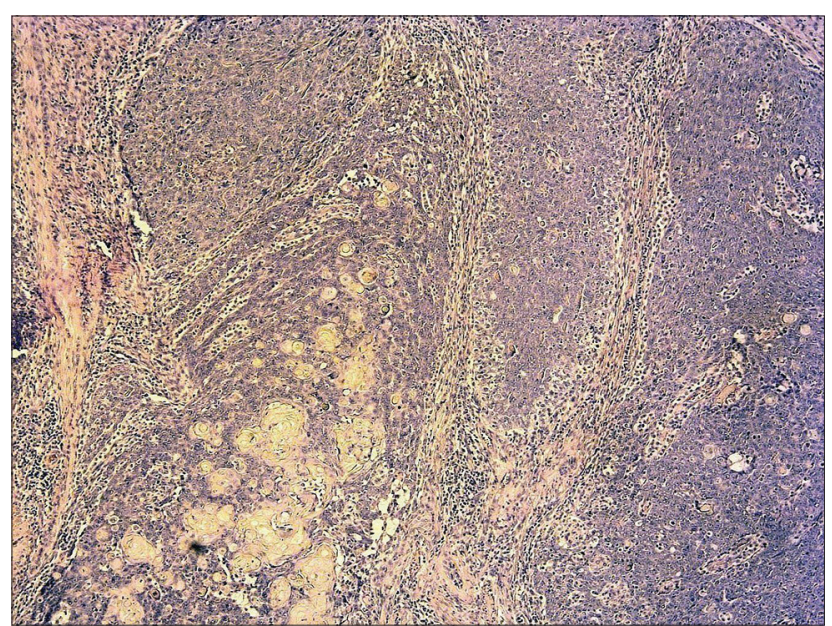

Figure 1: Predominant pleomorphic basaloid tumor cell population admixed with aggregates of eosinophilic anuclear cells and whorls of pink keratin material. (H\&E, original magnification 40x).

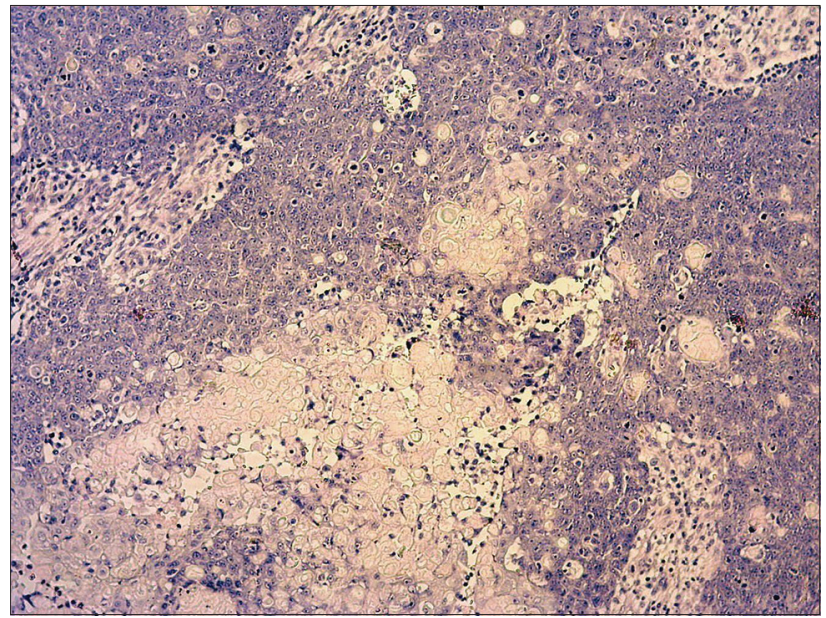

Figure 2: Detail on interface between basaloid tumor part and anuclear eosinophilic cells reminiscent of "shadow" cells, as well as whorls of keratin squamoid structures. (H\&E, original magnification 200x).

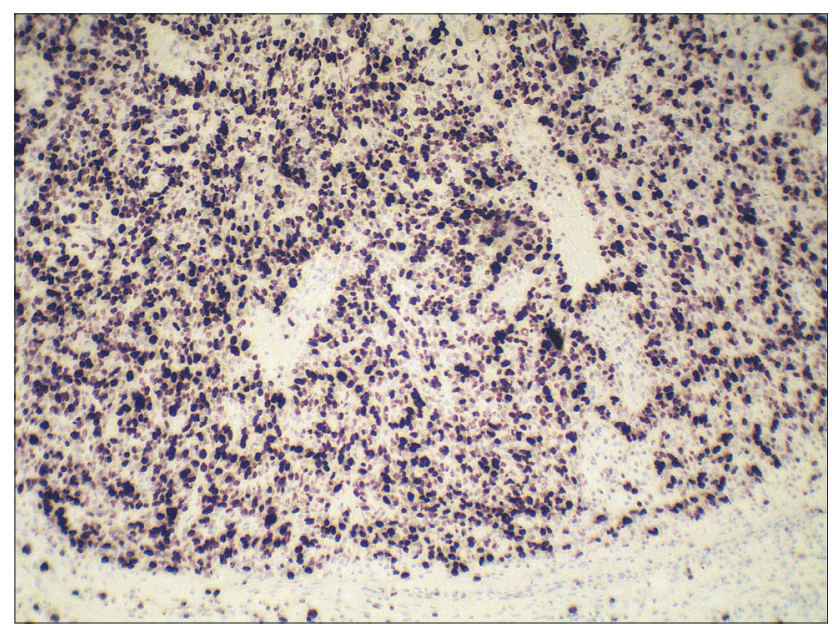

Figure 3: High proliferative activity (Ki-67 index) of basaloid cell population. (original magnification 200x).
Ki-67 index reached 90\% (Fig. 3) and more than 40 mitotic figures per 10 high power fields were counted. Immunohistochemically, the basaloid tumor part was apparently positive for CD10, pl20catenin and CD138 and very sporadically positive for cytokeratin 19 and BerEP4 (both < 5\% of cells). Cytokeratin 20 was negative and epithelial membrane antigen (Fig. 4) labelled only eosinophilic squamoid structures and "shadow" cells. Interestingly, in certain areas, numerous interspersed dentritic melanocytes strongly immunoreactive for S-100 protein were arranged singly and in larger expansile nests within basaloid tumor mass (Fig. 5). The tumor extended into the epidermis, resulting in focal ulceration. At the base, it grew invasively with infiltration of the dermis. Neither lymphovascular nor perineural tumor invasion was found. A spectrum of histomorphological findings along with immunophenotype favored a diagnosis of pilomatrical carcinoma with intratumorous melanocytic proliferation. Resection margins were free of tumor and a minimum of $5-\mathrm{mm}$ clearance was achieved. The patient continued to be under close follow-up and at the time this report was written (16 months after operation), no evidence of local recurrence or distant metastasis have been found.

\section{DISCUSSION}

$\mathrm{PC}$ is exceedingly rare cutaneous malignancy derived from the hair follicle matrix. It shows a predilection for middle aged and elderly individuals [3,4], but the cases involving the young people have also been described [5-7]. PC has no specific anatomic location and may arise anywhere in the body. Although it has been shown a slight predilection for the head and neck region [3,4,8-12], various other sites affected have been reported to date, such as the back $[3,13]$, chest $[3,4]$, upper limbs $[3,7,14]$, lower limbs [2,15], buttock [3] or vulva [5].

Table 1: Details of the primary antibodies and the corresponding detection systems used in the present case

\begin{tabular}{llll}
\hline Antigen & Antibody & Source & Dilution \\
\hline Ki-67 & monoclonal, clone MM1 & Leica & $1: 200$ \\
CD10 & monoclonal, clone 56C6 & Dako & ready to use \\
p120catenin & monoclonal, clone MRQ-5 & Dako & $1: 25$ \\
CD138 & monoclonal, clone MI15 & Dako & ready to use \\
$\begin{array}{l}\text { cytokeratin 19 } \\
\text { cytokeratin 20 }\end{array}$ & monoclonal, clone RCK108 & Dako & ready to use \\
epithelial antigen & monoclonal, clone Ks20.8 & Dako & $1: 50$ \\
$\begin{array}{l}\text { epithelial } \\
\text { membrane }\end{array}$ & monoclonal, clone BerEP4 & Dako & ready to use \\
$\begin{array}{l}\text { antigen } \\
\text { S-100 protein }\end{array}$ & monoclonal, clone 15E2E2 & Bako & $1: 100$ \\
\hline
\end{tabular}




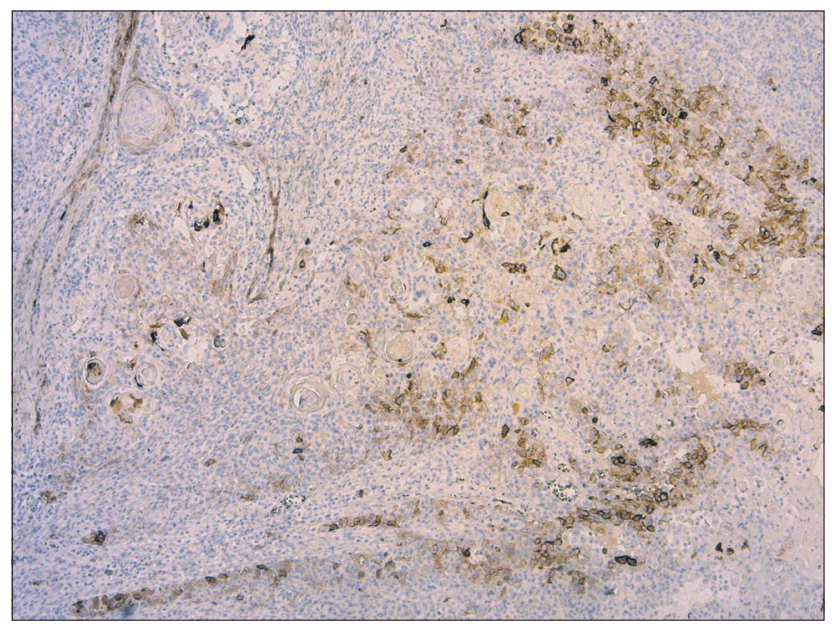

Figure 4: Positivity for EMA in eosinophilic tumor component, while basaloid tumor population is negative. (original magnification 100x).

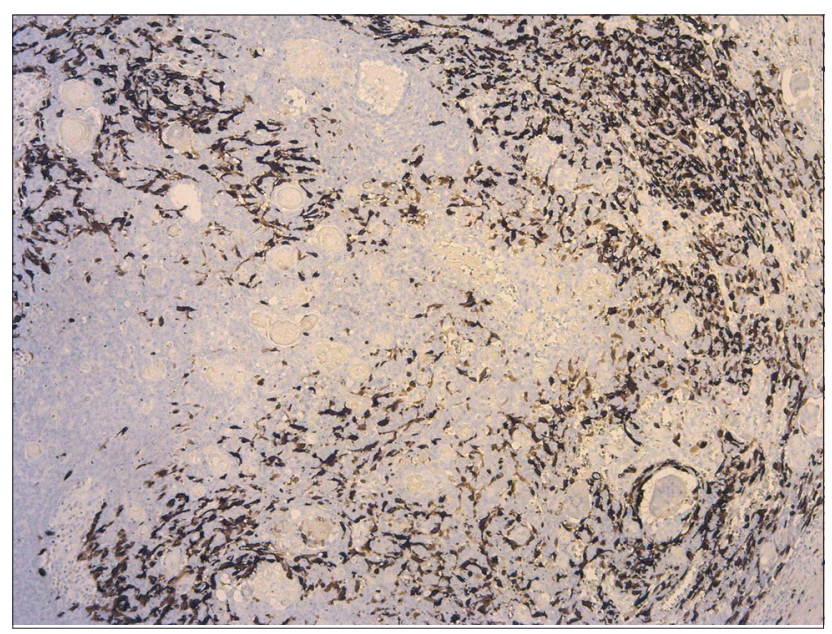

Figure 5: Strong positivity for S-100 protein in dentritic melanocytes interspersed within basaloid tumor mass. (original magnification 100x).

The origin of PC still controversial. Based on the literature research, the vast majority of the cases have been shown without histologic association with its benign counterpart, the finding supporting the development $a b$ initio. Nevertheless, the literature notes some case reports of patients in whom a biopsy specimen first identified the tumor as a benign lesion that underwent carcinomatous changes after a certain period of latency $[6,10,15]$. In the present case, we did not observe any benign tumor component within the tumor mass, so it was probably malignant from the onset. In this regard, it should be mentioned that although $\mathrm{PC}$ is a malignant counterpart of pilomatrixoma, and both tumors share common histopathologic and immunophenotypic features, their epidemiology is different. While benign pilomatrixomas are seen more often in women (female/male ratio 3:1), PCs are seen in the opposite ratio (female/male ratio $1: 3-5$ ) $[3,4,14]$.
Further, pilomatrixomas typically occur in children and young adults, but PCs usually occur in older people in the $5^{\text {th }}$ and $6^{\text {th }}$ decades of life $[4,14]$.

A definite diagnosis of $\mathrm{PC}$ and in particular, its differentiating from pilomatrixoma remains based only on the histomorphological features. However, much of the histopathology of PC resembles its benign counterpart and the criteria of malignancy have not been well established. In general, these include tumor asymmetry, poor circumscription, marked anaplasia of basaloid neoplastic cells with vesicular nuclei and prominent nucleoli, frequent atypical mitoses, areas of necrosis, infiltrative growth pattern, sometimes ulceration and vascular and/or perineural invasion $[4,12,15]$. In our case, the vast majority of them have been clearly visible confirming a malignancy. PC possess no specific immunoprofile and immunohistochemistry studies have not yielded markers that may consistently and definitively confirm a diagnosis. Moreover, many case reports published until now have not performed special immunoanalyses. In general, benign and malignant cutaneous adnexal tumors of follicular origin variably express the "hair differentiation" keratins, such as cytokeratin 7, 8, 18 and 19 [16]. In both, pilomatrixoma and PC, the basaloid cells showed a nuclear and cytoplasmic expression of $\beta$-catenin [17] and in pilomatrixoma, they showed strong positivity for CD138 and CDl0 [18]. Two papers $[7,12]$ also demonstrated a reactivity for BerEP4 in PC.

An interesting feature in our case was a remarkable population of dentritic melanocytes within a basaloid tumor tissue. In the last years, there were reported the cases of PCs accompanied by marked intratumorous melanocytes colonisation $[2,11,13,19]$. The terminology of this entity is inconsistent, since it has been entitled as melanocytic pilomatrix carcinoma [13], pilomatrix carcinoma with intralesional melanocytes [11], matrical carcinoma with melanocytic proliferation [2], or matrical carcinoma with prominent melanocytic hyperplasia [19]. Nevertheless, they are likely the same tumor entity under the different names. We believe that our current lesion represents an additional case of this unique variant. This histologic feature probably recapitulates the intimate relationship existing between matrical epithelium and melanocytes in the embryonal hair follicle or in the anagen stage of the hair cycle. Theoretically, a presence of numerous melanocytes in PC should not be surprising, but is in fact a very unusual feature. In the series of 20 PCs published by 
Sau et al. [3], immunohistochemical stain for S-100 protein was negative in all tumors.

From the clinical point of view, PC usually behaves like a low-grade malignancy, but it possess a high propensity for local recurrence. In the study of Sau et al. [3], approximately half of the cases investigated relapsed. A few PCs with regional and/or visceral metastases have been published until now $[3,8,9]$, some of which have led to death within a relatively short period from time of diagnosis [8,9]. Although PC metastasizes in only about $10 \%$ of the cases, when it becomes metastatic, a mortality rate approaches nearly $100 \%$ [14]. Therefore, a close clinical follow-up after diagnosis is a priority for further managment of the patient.

In conclusion, we described a unique case of PC accompanied by intratumorous melanocytic proliferation. To the best of our knowledge, only a few such cases have been published untill now. The biologic significance of melanocytic proliferation in this rare cutaneous neoplasm is uncertain and requires further study. It would be interesting to analyze larger number of the cases to elucidate, whether they may be considered a distinct histologic variant of PC with possibly different biological behaviour.

\section{Consent}

The examination of the patient was conducted according to the Declaration of Helsinki principles.

\section{REFERENCES}

1. Lopansri S, Mihm MC Jr. Pilomatrix carcinoma or calcifying epitheliocarcinoma of Malherbe: a case report and review of literature. Cancer. 1980;45:2368-73.

2. Villada G, Romagosa R, Miteva M, Romanelli P. Matrical carcinoma with melanocytic proliferation and prominent squamoid whorls. Am J Dermatopathol. 2016;38:e11-4.

3. Sau P, Lupton GP, Graham JH. Pilomatrix carcinoma. Cancer. 1993;71:2493-8.

4. Hardisson D, Lineares MD, Cuevas-Santos J, Contreras F. Pilomatrix carcinoma: a clinicopathologic study of six cases and review of the literature. Am J Dermatopathol. 2001;23:394-401.

5. Song M, Chekmareva M, Bachmann G, Gibbon D. Pilomatrix carcinoma of the vulva. Gynecol Oncol Rep. 2015;15:9-11.

6. Nishioka M, Tanemura A, Yamanaka T, Tani M, Miura H, Asakura M, et al. Pilomatrix carcinoma arising from pilomatricoma after 10-year senescent period: Immunohistochemical analysis. J Dermatol. 2010;37:735-9.

7. Sato S, Nakamura Y, Shimizu M, Yamada K, Teramoto Y, Yamazaki N, et al. Giant pedunculated pilomatrix carcinoma on the upper limb: A rare clinical appearance. Eur J Dermatol. 2015;25:91-2.

8. Bremnes RM, Kvamme JM, Stalsberg H, Jacobsen EA. Pilomatrix carcinoma with multiple metastases: Report of a case and review of the literature. Eur J Cancer. 1999;35:433-7.

9. Nieddermeyer HP, Peris K, Höfler H. Pilomatrix carcinoma with multiple visceral metastases. Report of a case. Cancer. 1996;77:1311-4.

10. Sassmanshausen J, Chaffins M. Pilomatrix carcinoma: A report of a case arising from a previously excised pilomatrixoma and review of the literature. J Am Acad Dermatol. 2001;44(2 Suppl):358-61.

11. Jani P, Chetty R, Ghazarian DM. An unusual composite pilomatrix carcinoma with intralesional melanocytes: differential diagnosis, immunohistochemical evaluation, and review of the literature. Am J Dermatopathol. 2008;30:174-7.

12. Alcántara-Gonzáles J, Sánchez-Largo ME, Caminoa A, Erana I, Calzado-Villareal L. Pilomatrix carcinoma: a rare cause of facial tumor. Dermatol Online J. 2014;20:8.

13. Soler AP, Kindel SE, McCloskey G, Burchette JL. Cell-cell adhesion proteins in melanocytic pilomatrix carcinoma. Rare Tumors. 2010;2:e43.

14. Scheinfeld N. Pilomatrical carcinoma: a case in a patient with HIV and hepatitis C. Dermatol Online J. 2008;14:4.

15. Allaoui M, Hubert E, Michels JJ. Malignant pilomatricoma: two new observations and review of the relevant literature. Turk Patoloji Derg. 2014;30:66-8.

16. Leonardo E. Morfologia Molecolare. Principi generali e diagnostica sistematica. Padova, Italy. 2011; 800 p. ISBN-13 978-88-6292-201-2

17. Hassanein AM, Glanz SM. Beta-catenin expression in benign and malignant pilomatrix neoplasms. Br J Dermatol. 2004;150:511-6.

18. Rumayor A, Carlos R, Kirsch HM, de Andrade BA, Romañach MJ, de Almeida OP. Ghost cells in pilomatrixoma, craniopharyngioma, and calcifying cystic odontogenic tumor: histological, immunohistochemical, and ultrastructural study. J Oral Pathol Med. 2015;44:284-90.

19. Monteagudo C, Fernández-Figueras MT, San-Juan J, Lopez D, Carda C. Matrical carcinoma with prominent melanocytic hyperplasia (malignant melanocytic matricoma?) A report of two cases. Am J Dermatopathol. 2003;25:485-9.

Copyright by Vladimír Bartoš, et al. This is an open-access article distributed under the terms of the Creative Commons Attribution License, which permits unrestricted use, distribution, and reproduction in any medium, provided the original author and source are credited. Source of Support: Nil, Conflict of Interest: None declared. 